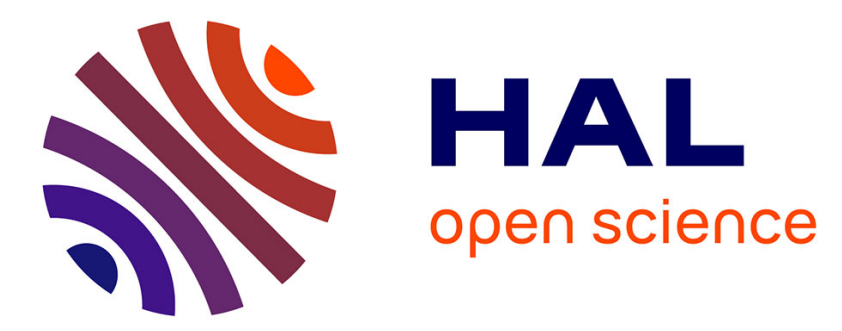

\title{
Structure of a Flat Plate Boundary Layer Subjected to Free-Stream Turbulence
}

Frédéric Péneau, Henri Claude Boisson, Alain Kondjoyan, Ned Djilali

\section{To cite this version:}

Frédéric Péneau, Henri Claude Boisson, Alain Kondjoyan, Ned Djilali. Structure of a Flat Plate Boundary Layer Subjected to Free-Stream Turbulence. International Journal of Computational Fluid Dynamics, 2007, 18 (2), pp.175-188. 10.1080/10618560310001634177 . hal-02952882

\section{HAL Id: hal-02952882 \\ https://hal.inrae.fr/hal-02952882}

Submitted on 17 May 2021

HAL is a multi-disciplinary open access archive for the deposit and dissemination of scientific research documents, whether they are published or not. The documents may come from teaching and research institutions in France or abroad, or from public or private research centers.
L'archive ouverte pluridisciplinaire $\mathbf{H A L}$, est destinée au dépôt et à la diffusion de documents scientifiques de niveau recherche, publiés ou non, émanant des établissements d'enseignement et de recherche français ou étrangers, des laboratoires publics ou privés.

\section{(c)(1)}

Distributed under a Creative Commons Attribution| 4.0 International License 


\title{
Structure of a Flat Plate Boundary Layer Subjected to Free-Stream Turbulence
}

\author{
FRÉDÉRIC PÉNEAU ${ }^{\mathrm{a}, *}$, HENRI CLAUDE BOISSON ${ }^{\mathrm{b}}$, ALAIN KONDJOYAN $^{\mathrm{c}}$ and NED DJILALI ${ }^{\mathrm{d}}$
}

${ }^{\mathrm{a}}$ CERAM EAI Tech, 157 rue Albert Einstein, BP 085, 06902 Sophia Antipolis Cedex, France; ${ }^{\mathrm{b}}$ IMFT, av Pr Camille Soula, 31400 Toulouse, France; ${ }^{\mathrm{c}}$ INRA, S.R.V., 63122 Saint Genès Champanelle, France; ${ }^{\mathrm{d}}$ Department of Mechanical Engineering, University of Victoria, Victoria, BC, Canada V8W $3 P 6$

\begin{abstract}
The structure near the flat plate leading edge of an incompressible boundary layer subjected to freestream turbulence is investigated using large eddy simulation (LES) with a dynamic mixed subgridscale model. Free-stream turbulent intensities ranging from 1.5 to $10 \%$ are investigated. The evolutions of the velocity, temperature and turbulent intensity profiles inside the boundary layer and the characteristic length scales are analyzed and compared to a laminar flat plate boundary layer. The impact of the free-stream turbulence is examined for Reynolds numbers ranging from 0 (leading edge of the flat plate) to $R e_{x}=80,000$ by using two consecutive spatial LESs. Bypass transition is found to occur in the early stage of the boundary layer development for all five cases presented here. The analysis indicates that the thermal turbulent structures transfer more energy and hence generate more thermal fluctuations in their wake than the dynamic structures.
\end{abstract}

Keywords: Heat transfer; Free-stream turbulence; Flat plate boundary layer; Large eddy simulations

\section{NOMENCLATURE}

\begin{tabular}{|c|c|c|c|}
\hline$C_{f}$ & $\begin{array}{l}\text { Friction coefficient with } \\
\text { free-stream turbulence }\end{array}$ & $R e_{\theta}=\frac{U_{e} \theta}{\nu}$ & $\begin{array}{l}\text { Reynolds number based on } \\
\text { the local momentum }\end{array}$ \\
\hline$C_{f_{0}}$ & Friction coefficient without & & thickness $\theta$ \\
\hline & free-stream turbulence & St & Stanton number with \\
\hline$D=\frac{\lambda}{\rho C}$ & Thermal diffusivity & & free-stream turbulence \\
\hline$D_{t}$ & $\begin{array}{l}\text { Subgrid diffusivity, turbulent } \\
\text { diffusivity }=\left\langle\vartheta^{\prime} T^{\prime}\right\rangle / \partial T / \partial y\end{array}$ & $\mathrm{St}_{0}$ & $\begin{array}{l}\text { Stanton number without } \\
\text { free-stream turbulence }\end{array}$ \\
\hline$I u=\frac{\sqrt{u_{\mathrm{rms}}^{2}+v_{\mathrm{rms}}^{2}+w_{\mathrm{rms}}^{2}}}{U_{e}}$ & Turbulent intensity & $T=T_{\text {mean }}+T^{\prime}$ & $\begin{array}{l}\text { Reynolds decomposition } \\
\text { for the temperature field }\end{array}$ \\
\hline$h, h_{e}, h_{w}$ & $\begin{array}{l}\text { Fluid enthalpy, free-stream } \\
\text { fluid enthalpy and wall } \\
\text { fluid enthalpy }\end{array}$ & $\begin{array}{l}T_{\text {mean }} \\
T\end{array}$ & $\begin{array}{l}\text { Mean temperature } \\
\text { Temperature fluctuations } \\
\left\langle T^{\prime}\right\rangle=0\end{array}$ \\
\hline$L_{\varepsilon}=\frac{\left\langle q_{e}^{2}\right\rangle^{3 / 2}}{U_{e} \frac{\partial\left\langle q_{e}^{2}\right\rangle}{\partial x}}$ & $\begin{array}{l}\text { Free-stream turbulence } \\
\text { dissipative } \\
\text { length-scale }\end{array}$ & $\begin{array}{l}T_{\mathrm{rms}}=\left\langle T^{\prime} T^{\prime}\right\rangle^{0.5} \\
T=\bar{T}+T^{\prime \prime}\end{array}$ & $\begin{array}{l}\text { Temperature turbulent level } \\
\text { Large eddy decomposition } \\
\text { for the temperature field }\end{array}$ \\
\hline$P=\bar{P}+P^{\prime \prime}$ & $\begin{array}{l}\text { Large eddy decomposition } \\
\text { for the pressure field }\end{array}$ & $\begin{array}{l}\bar{T} \\
T^{\prime \prime}\end{array}$ & $\begin{array}{l}\text { Resolved temperature field } \\
\text { Subgrid temperature field }\end{array}$ \\
\hline $\bar{P}$ & Resolved pressure field & $T u=\frac{u_{\mathrm{ms}}}{U}$ & Turbulent level \\
\hline$P^{\prime \prime}$ & Subgrid pressure field & $u_{i}=U_{i}^{e}+u_{i}^{\prime}$ & Reynolds decomposition \\
\hline $\operatorname{Pr}=\frac{\nu}{D}$ & Prandtl number & & for the velocity field \\
\hline $\operatorname{Pr}_{t}=\frac{\nu_{t}}{u_{t_{4}}^{2} v^{2}+w^{2}}$ & Turbulent Prandtl number & $U_{i}$ & Mean velocity field; $U_{1}=U$ \\
\hline $\begin{array}{l}q_{e}=\frac{u_{\mathrm{rms}}+v_{\mathrm{rms}}+w_{\mathrm{rms}}}{\nu} \\
R e_{x}=\frac{U_{e} x}{\nu}\end{array}$ & $\begin{array}{l}\text { Turbulent kinetic energy } \\
\text { Reynolds number based } \\
\text { on the distance from } \\
\text { the leading edge ' } x \text { ' }\end{array}$ & & $\begin{array}{l}\text { longitudinal direction; } \\
U_{2}=V \text { lateral direction; } \\
U_{3}=W \text { span-wise } \\
\text { direction }\end{array}$ \\
\hline
\end{tabular}

*Corresponding author. E-mail: frederic.peneau@cote-azur.cci.fr 


$\begin{array}{lc}\begin{array}{l}u_{i}^{\prime} \text { Velocity } \\ \text { fluctuations }\end{array} & u_{1}^{\prime}=u^{\prime} \text { longitudinal direction; } \\ \left\langle u_{i}^{\prime}\right\rangle=0 & u_{2}^{\prime}=v^{\prime} \text { lateral direction; } \\ u_{3}^{\prime}=w^{\prime} \text { spanwise direction. } & \text { Mean free-stream longitudinal } \\ & \text { velocity component } \\ u_{i}=\bar{u}_{i}+u_{i}^{\prime \prime} & \text { Large eddy decomposition } \\ & \text { for the velocity field } \\ \bar{u}_{i} & \text { Resolved velocity field } \\ u_{i}^{\prime \prime} & \text { Subgrid velocity field } \\ u_{\mathrm{rms}}=\left\langle u_{1}^{\prime} u_{1}^{\prime}\right\rangle^{0.5} & \text { Longitudinal turbulent } \\ & \text { fluctuations } \\ v_{\mathrm{rms}}=\left\langle u_{2}^{\prime} u_{2}^{\prime}\right\rangle^{0.5} & \text { Lateral turbulent fluctuations } \\ w_{\mathrm{rms}}=\left\langle u_{3}^{\prime} u_{3}^{\prime}\right\rangle^{0.5} & \text { Span-wise turbulent } \\ \delta & \text { fluctuations } \\ \delta_{T} & \text { Dynamic boundary layer } \\ \delta_{1}=\int_{0}^{\infty}\left(1-\frac{U}{U_{e}}\right) \mathrm{d} y & \text { thickness } \\ & \text { Thermal boundary } \\ & \text { layer thickness } \\ & \text { Displacement thickness }\end{array}$

\section{INTRODUCTION}

The influence of high free-stream turbulence on the dynamics and heat transfer of boundary layer flows is relevant to many industrial applications and has been the subject of experimental and theoretical research for some time. The first studies were performed in the thirties by Fage and Falkner (1931) who did not observe any influence on heat transfer in the presumed laminar region. Due to discrepancies and contradictions in reported findings, the field remained wide open until the landmark work of Bradshaw (1974). In a series of studies with his team, (Simonich and Bradshaw, 1978; Hancock and Bradshaw, 1983, 1989; Baskaran et al., 1989), Bradshaw and his group analyzed the influence of free-stream turbulence not only in terms of the turbulence level $\mathrm{Tu}$ but also in terms of the turbulent length scale $L_{\epsilon}$. It was found that if $L_{\epsilon}$ is too small with respect to the boundary layer length scale, then the freestream turbulent structures dissipate before reaching the surface of the plate with no increase in the dynamic activities of the flow or in heat transfer. In his report of 1974, Bradshaw noted the importance of the work of Charnay et al. (1971, 1972, 1976) on the interaction mechanisms between the free-stream flow and the wake of the boundary layer. A few years later, Dyban et al. (1977), Dyban and Epick (1985) published a very interesting and original work on the influence of free-stream turbulence on the laminar region of the boundary layer. With the focus of both academic and industrial research at that time on turbulent flow, Dyban et al.'s work did not receive the attention it deserved. An increase of $56 \%$ in the friction coefficient was observed at low Reynolds numbers $(<20,000)$ with a free-stream turbulence level of $12.5 \%$. These results underscored the importance of the interaction between the boundary layer and the free-stream near the leading edge. Meanwhile, a consensus has emerged from the numerous studies on

$$
\begin{aligned}
& \delta_{3}=\int^{\infty} \frac{U}{U_{e}} \quad \text { Kinetic energy } \\
& \text { thickness } \\
& { }^{0} \times\left(1-\left(\frac{U}{U_{e}}\right)^{2}\right) \mathrm{d} y \\
& \Delta=\int_{0}^{\infty} \frac{U}{U_{e}}\left(\frac{h_{e}-h}{h_{e}-h_{w}}\right) \mathrm{d} y \quad \begin{array}{c}
\text { Enthalpy } \\
\text { thickness }
\end{array} \\
& \theta=\int_{0}^{\infty} \frac{U}{U_{e}}\left(1-\frac{U}{U_{e}}\right) \mathrm{d} y \quad \text { Momentum thickness } \\
& \lambda \quad \text { Thermal conductivity } \\
& \mu \quad \text { Dynamic viscosity } \\
& \nu=\frac{\mu}{\rho} \quad \text { Kinematic viscosity } \\
& \nu_{t} \\
& \rho \\
& \langle\rangle \\
& \text { Subgrid viscosity, turbulent } \\
& \text { viscosity }=\left\langle u^{\prime} v^{\prime}\right\rangle / \partial U / \partial y \\
& \text { Fluid density } \\
& \text { Average operator in the span- } \\
& \text { wise direction and in time }
\end{aligned}
$$

turbulent boundary layers. Free-stream turbulence does increase the dynamic and heat transfer in the turbulent boundary layer and heat transfer seems to be more sensitive to free-stream turbulence (Pédisius et al., 1979; Meier and Kreplin, 1980; Blair, 1983a,b). Although this conclusion is general, there is considerable variation from study to study on the magnitude of the heat transfer enhancement. Several studies in the $80 \mathrm{~s}$ and $90 \mathrm{~s}$ attempted to model these phenomena with varying success (Young et al., 1992; Maciejewski and Moffat, 1992). A review of the main experimental work can be found in Kondjoyan et al. (2002).

In this paper we present a numerical analysis of the influence of free-stream turbulence on the "laminar" boundary layer. Our results are compared to the experimental data of Dyban et al. (1977) and Dyban and Epick (1985) and we propose an interpretation of the observed phenomena. The paper provides first an overview of the numerical model, the computational procedure and the physical characteristics of the problem. We then present the evolution of the velocity and temperature profiles inside the boundary layer in the presence of free-stream turbulence. The turbulent intensity and turbulent energy production profiles are examined and compared to those for a turbulent boundary layer with no free-stream turbulence. Finally, a physical interpretation of the results is proposed based on an analysis of the Reynolds stresses and turbulent Prandtl number.

\section{NUMERICAL METHOD AND SUBGRID MODELING}

\section{The LES Equations and the Subgrid-scale Model}

The LES equations are obtained by introducing the following decomposition in the Navier-Stokes equations:

$$
u_{i}=\bar{u}_{i}+u_{i}^{\prime \prime}
$$


where $\bar{u}_{i}$ represents the implicitly filtered, resolved velocity field, and $u_{i}^{\prime \prime}$ represents the subgrid velocity field. This yields:

$$
\begin{gathered}
\frac{\partial \bar{u}_{i}}{\partial x_{i}}=0 \\
\frac{\partial \bar{u}_{i}}{\partial t}+\frac{\partial \bar{u}_{i} \bar{u}_{j}}{\partial x_{j}}=-\frac{\partial \bar{p}}{\partial x_{i}}+\frac{\partial\left(2 \nu \bar{S}_{i j}-\tau_{i j}\right)}{\partial x_{j}}
\end{gathered}
$$

where

$$
\tau=\overline{u_{i} u_{j}}-\bar{u}_{i} \bar{u}_{j}=L_{i j}+C_{i j}+R_{i j}
$$

with

$$
\begin{gathered}
L_{i j}=\overline{\bar{u}_{i} \bar{u}_{j}}-\overline{\bar{u}_{i}} \overline{\bar{u}_{j}} \\
C_{i j}=\overline{\bar{u}_{i} u_{j}^{\prime \prime}}+\overline{\bar{u}_{j} u_{i}^{\prime \prime}}-\left(\overline{\bar{u}_{i}} \overline{u_{j}^{\prime \prime}}+\overline{\bar{u}_{j}} \overline{u_{i}^{\prime \prime}}\right) \\
R_{i j}=\overline{u_{i}^{\prime \prime} u_{j}^{\prime \prime}}-\overline{u_{i}^{\prime \prime}} \overline{u_{j}^{\prime \prime}} \\
\bar{p}=\bar{P}+\left(C_{k k}+R_{k k}\right) / 3 .
\end{gathered}
$$

$L_{i j}$ is calculated explicitly, while $C_{i j}$ and $R_{i j}$ are modeled using the classical concept of subgrid viscosity $\nu_{t}$ proposed by Smagorinsky (1963) in conjunction with the dynamic mixed model (DMM) of Zang et al. (1993):

$$
C_{i j}+R_{i j}=-\nu_{t} \overline{S_{i j}} \text { for } i \neq j .
$$

With this model $\nu_{t}$ is a function of space and time. $C_{k k}$ and $R_{k k}$ are incorporated into the pressure terms because of the incompressibility condition. For further details on the DMM and the calculation procedure for evaluating $\nu_{t}$, the reader is referred to Péneau et al. (1999). The introduction of a similar decomposition into the energy equation yields:

$$
\frac{\partial \bar{T}}{\partial t}+\frac{\partial \bar{T} \bar{u}_{j}}{\partial x_{j}}=\frac{\partial\left(D \frac{\partial \bar{T}}{\partial x_{j}}\right)-q_{j}}{\partial x_{j}}
$$

with

$$
q_{j}=\overline{T u_{j}}=\bar{T} \bar{u}_{j}=L c_{j}+C c_{j}+R c_{j}
$$

Again, $L c_{j}$ is calculated explicitly while $C c_{j}$ and $R c_{j}$ are modeled using

$$
C c_{j}+R c_{j}=-D_{t} \frac{\partial \bar{T}}{\partial x_{j}}
$$

\section{The Numerical Method}

The numerical simulations are carried out using JADIM code (Calmet and Magnaudet, 1996). The momentum and scalar equations are discretized using a finite volume method with a second-order centered scheme on a staggered grid. The solution is advanced in time using a three-step Runge-Kutta procedure. The nonlinear terms are computed explicitly while the diffusive terms are calculated using the semi-implicit Crank-Nicholson algorithm. To satisfy the incompressibility condition, a Poisson equation is solved by combining a direct inversion in the $(x, y)$ (longitudinal and lateral direction, respectively) plane with a spectral Fourier method in the third direction $z$ (transversal direction). For more details on JADIM the reader is referred to Calmet and Magnaudet (1996).

\section{Grid and Physical Parameter}

The grid on which the spatial simulations are performed was initially designed to simulate a fully turbulent boundary layer with entrance Reynolds number, based on the displacement thickness $\delta_{1}, \operatorname{Re}_{\delta_{1}}=1620$. The dimensions of this domain are $L_{x}=85 \delta_{1}, L_{y}=50 \delta_{1}$ and $L_{z}=20 \delta_{1}$ with the following number of mesh points in the three direction $N_{x}=96, N_{y}=96$ and $N_{z}=64$. In wall units, the mesh size in the longitudinal and span-wise directions is $\Delta x^{+}=\left(\Delta x \cdot u_{\tau}\right) /(\nu)=38$ and $\Delta z^{+}=24$. In the previous equation $u_{\tau}$ is the friction velocity of a fully turbulent boundary layer at $\operatorname{Re}_{\delta_{1}}=1620$. Near the wall, the mesh is refined in the normal direction, with the first point located at $y^{+}=0.18$. The physical dimensions are $L_{x}=1.7 \mathrm{~m}, \quad L_{y}=1 \mathrm{~m}, \quad L_{z}=0.4 \mathrm{~m}$ and $\Delta x=1.04 \times 10^{-2} \mathrm{~m}$ and $\Delta z=0.625 \times 10^{-2} \mathrm{~m}$. This mesh, which proved to be well adapted for the simulation of a fully turbulent boundary layer (Péneau et al., 1999), is used to simulate the development under an air flow $(\mathrm{Pr}=0.72)$ boundary layer near the leading edge of a flat plate subjected to a free-stream turbulent field. The mean free-stream velocity is $U_{\mathrm{e}}=1.23 \mathrm{~m} / \mathrm{s}$. The free-stream temperature is $T_{\mathrm{e}}=273 \mathrm{~K}$ while the wall temperature is set to $T_{\mathrm{w}}=274 \mathrm{~K}$. Open boundary conditions are set as $\partial^{2} \bar{u}_{i} / \partial n^{2}=0$, where $n$ is the direction normal to the exit plane.

\section{THE HIGH FREE-STREAM TURBULENCE FIELD AND THE SPATIAL SIMULATION OF THE BOUNDARY LAYER}

The generation of the turbulent fields used as entrance conditions for our spatial large eddy simulation (LES) has been fully presented in Péneau et al. (2000). The same method was used here, utilizing the computational mesh described in the preceding section so that a larger range of length scale is covered and a better resolution of the vortices is achieved in the region near the wall. The resulting free-stream turbulence field as well as the boundary conditions used for the simulation are shown in Fig. 1. The velocity field corresponding to the middle yz plane is recorded for 1000 time steps, and is then used as an entrance condition for the spatial simulation of the boundary layer development.

Five cases of free-stream turbulence have been generated this way. Table I presents their turbulent characteristics. 


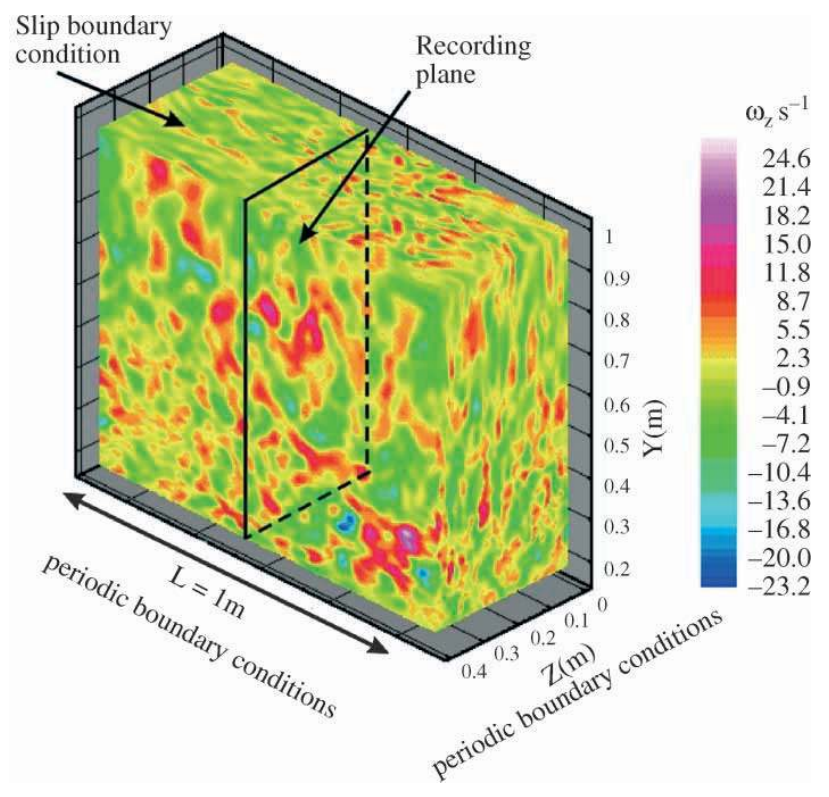

FIGURE 1 Lateral component of a typical free-stream vorticity field. (Colour version available to view online.)

Figures 2 and 3 show the turbulence level and intensity profiles for the five cases of free-stream turbulent fields investigated, and Fig. 4 shows the temporal evolution. The profiles presented were obtained by applying an averaging operator in the span-wise direction and in time (1000 time steps). " $y=0 \mathrm{~m}$ " corresponds to the position of the flat plate while " $y=1 \mathrm{~m}$ " corresponds to the north boundary of the domain of calculation. In this direction, the mesh size increases progressively and hence there is a decrease in the turbulent levels and intensities as we reach the north boundary.

This phenomenon is less important for cases D and E because these turbulent fields were generated with larger vortices which are better resolved and do not dissipate as much in this region. The root mean square velocity profiles for the five cases indicate that the turbulent fields are almost isotropic and homogeneous except near the north and south boundaries of the domain, again because of the boundary conditions imposed there. Note that a constant free-stream temperature field is imposed such that no rms temperature profile exists.

TABLE I Turbulent characteristics of the five free-stream turbulent fields generated

\begin{tabular}{lcc}
\hline & $T u$ in $\%$ & Iu in $\%$ \\
\hline Case A & 1 & 2 \\
Case B & 3 & 5 \\
Case C* & 3 & 5 \\
Case D & 5 & 8 \\
Case E & 10 & 16 \\
\hline
\end{tabular}

* The case $\mathrm{C}$ was generated with bigger vortices to analyse the influence of the turbulence length-scale on the wall transfer.

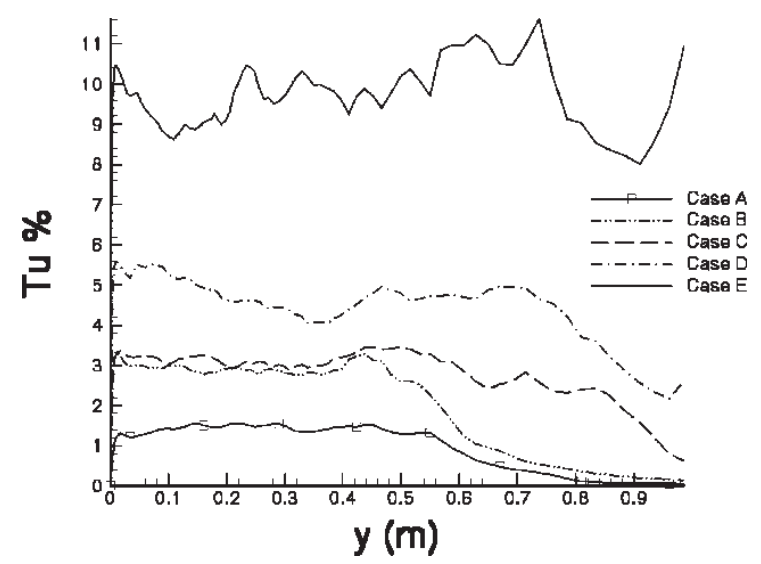

FIGURE 2 Turbulent level profiles.

The temporal evolution obtained by applying an averaging operator in the span-wise and lateral direction on the entrance velocity signals shows an exponential decay of the turbulence level similar to the spatial decay of grid-generated turbulence.

In order to extend the Reynolds number of the simulations, two successive spatial simulations were

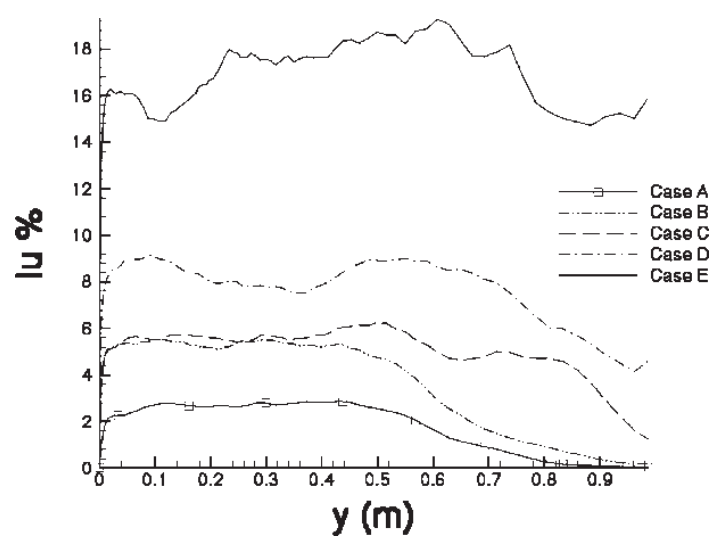

FIGURE 3 Turbulent intensity profiles.

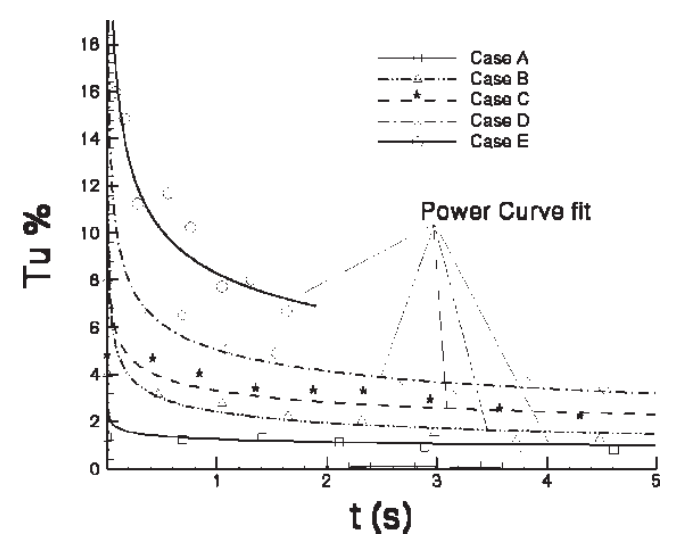

FIGURE 4 Temporal evolution of the turbulence levels. 


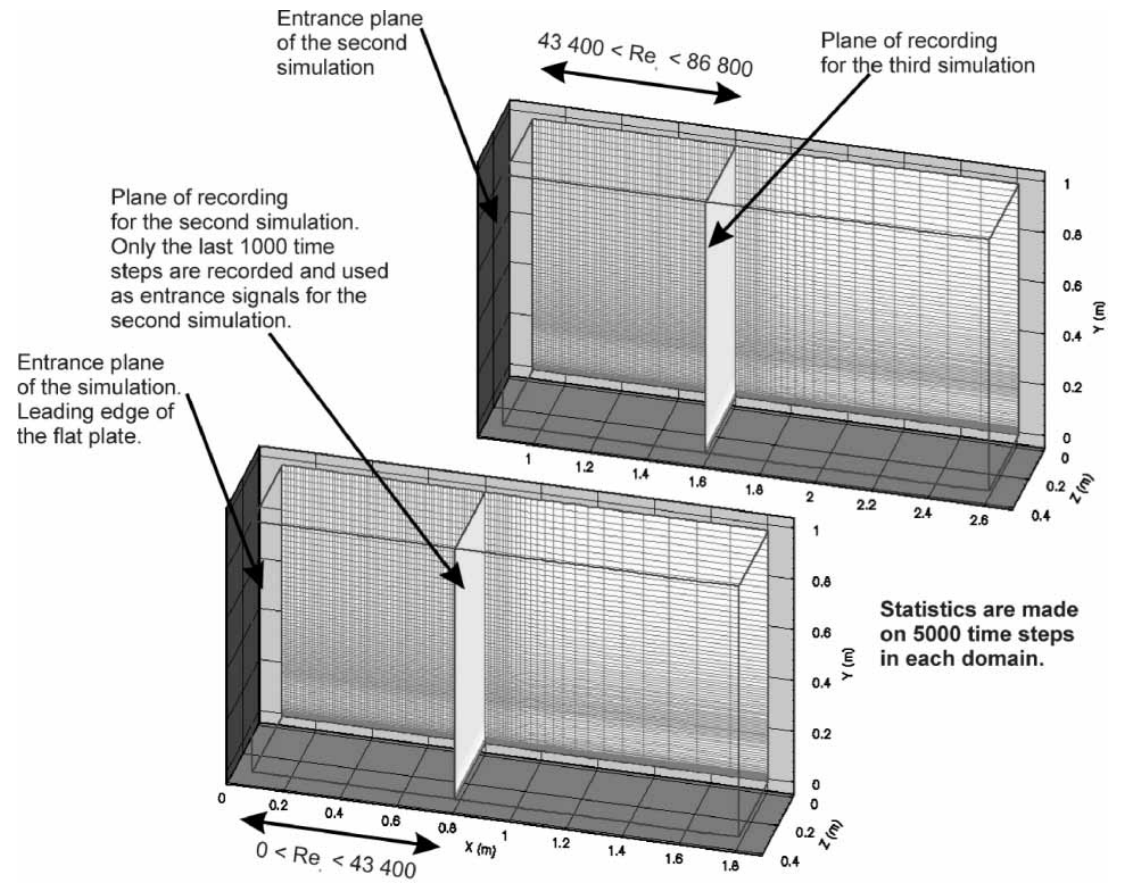

FIGURE 5 Method for spatial large eddy simulation by consecutive calculations.

performed as shown in Fig. 5. In the first domain of calculation (the bottom domain in Fig. 5) the 1000 time steps recorded from the free-stream turbulence field generation are used as entrance signal at the west boundary of the domain. At the south boundary, a no slip condition is imposed so that the arrival of a free-stream turbulence field on the leading edge of a flat plate is simulated. However, in order to avoid numerical instabilities, the no slip boundary condition on the longitudinal velocity component as well as the constant temperature condition are imposed progressively on the first cells of the domain in the $x$ direction. The resulting gradual "transition" can be observed in Figs. 6 and 7. Spatial LESs of a laminar boundary layer with no free-stream turbulence have been performed on the same domains with the same subgrid-scale model for $0 \leq R e_{x} \leq 200,000$ and have yielded perfect agreement with Blasius' solution. ${ }^{\dagger}$ Those simulations were performed using five successive simulations. The first two are used as initial fields for the simulations presented in the next paragraph.

The LESs were performed in the following way. For each domain only half of the box is considered as the last 16 cells in the longitudinal direction are progressively stretched before reaching the outflow boundary condition as one can observe in Fig. 5. For the calculation in the first domain $\left(0 \leq R e_{x} \leq 43,400\right)$, we start with the laminar boundary layer solution. The calculation is initiated and the freestream turbulent field enters the domain. The interaction of the free-stream turbulence with the laminar boundary layer then takes place. After 2000 time steps (requiring input from two calculations of 1000 time steps to impose recorded entrance signals) we start to compute the statistics over 5000 time steps. During the last 1000 time steps, velocity and temperature signals are also recorded to be used as entrance signals for the second calculation domain $\left(43,400 \leq R e_{x} \leq 86,800\right)$. With this method, if the statistics at the exit of the first domain of calculation are not equivalent to those at the entrance of the second one, this implies that the flow was not statistically converged in the first domain. For the second simulation we proceed in the same manner except that now the initial field is the one obtained without free-stream turbulence for $43,400 \leq R e_{x} \leq 86,800$.

\section{RESULTS}

Figures 6 and 7 show instantaneous velocity and temperature fields for case $\mathrm{E}(T u \approx 10 \%)$ for Reynolds number varying from $0(x=0 \mathrm{~m})$ up to 50,000 $(x \approx 0.9 \mathrm{~m})$. As observed earlier, the free-stream flow is maintained at a constant temperature. The formation of streak-like structures takes place rapidly after the leading edge for both fields. This supports the occurrence of bypass transition pointed out in Péneau et al. (2000).

In Figs. 8 and 9, ejection phenomena of equal intensity for both fields are observed.

Selective results representative of the evolution of the flow with the turbulence level are presented next. Figure 10 shows that up to $\operatorname{Re}_{x}=73,000$ the mean longitudinal velocity profiles remain virtually insensitive to low turbulence level. With increasing turbulent level

\footnotetext{
${ }^{\dagger}$ If we disregard the statistics in the first cell of the domain where the no slip condition is progressively imposed.
} 


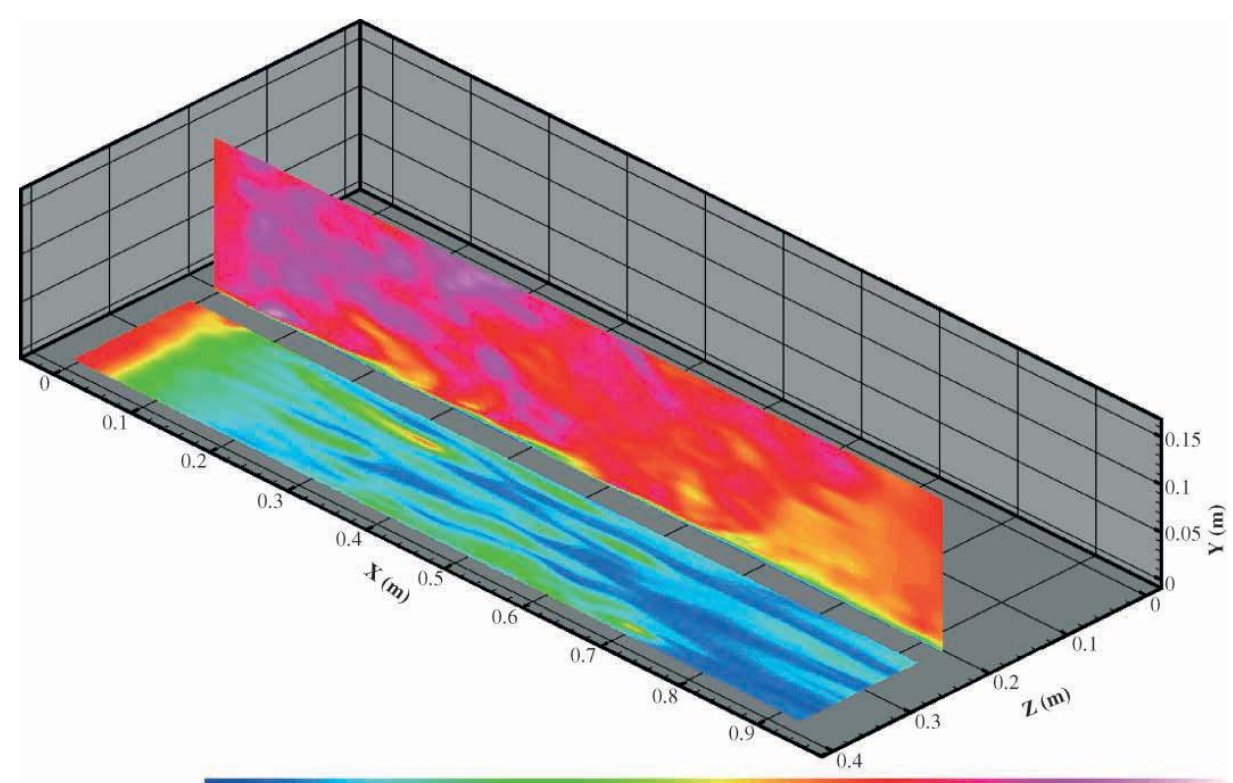

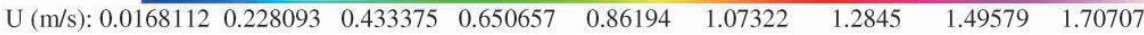

FIGURE 6 Instantaneous $x y$ and $z x$ plane velocity field; case E.

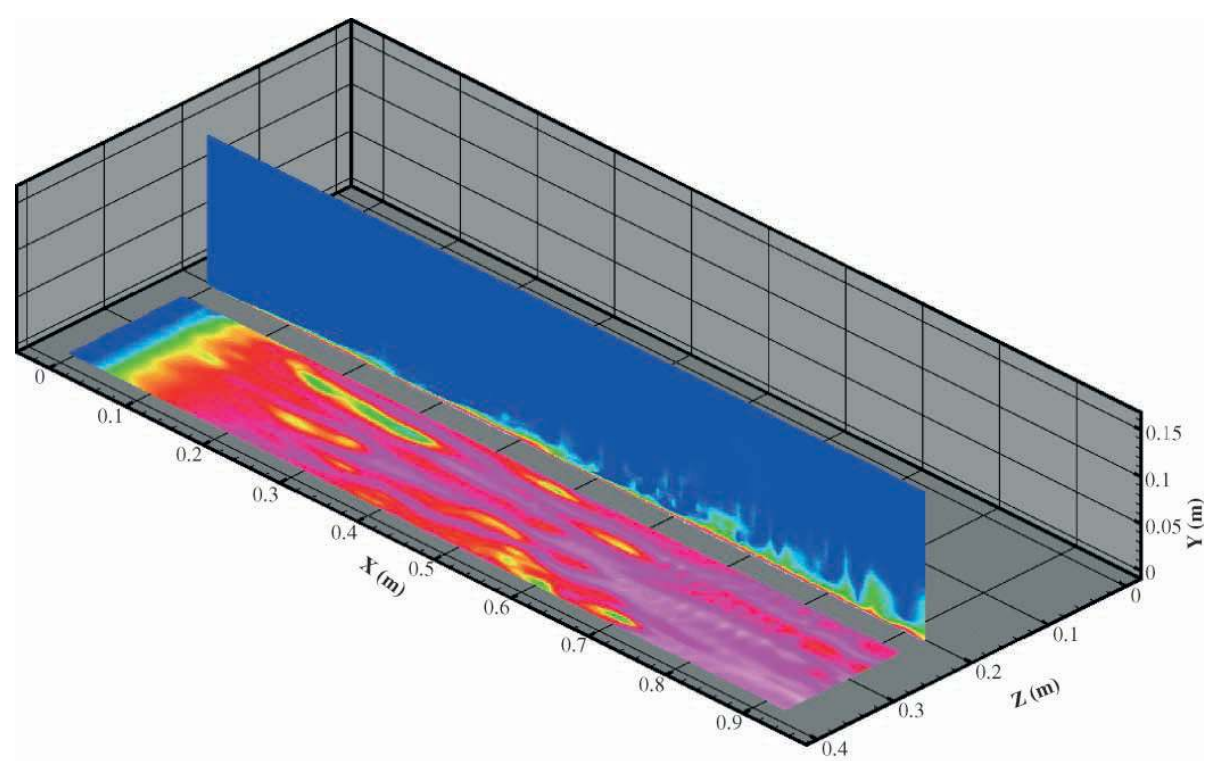

T: $273.004273 .102 \quad 273.2 \quad 273.298273 .396273 .495273 .593273 .691273 .789273 .887$

FIGURE 7 Instantaneous $x y$ and $z x$ plane temperature field; case E.

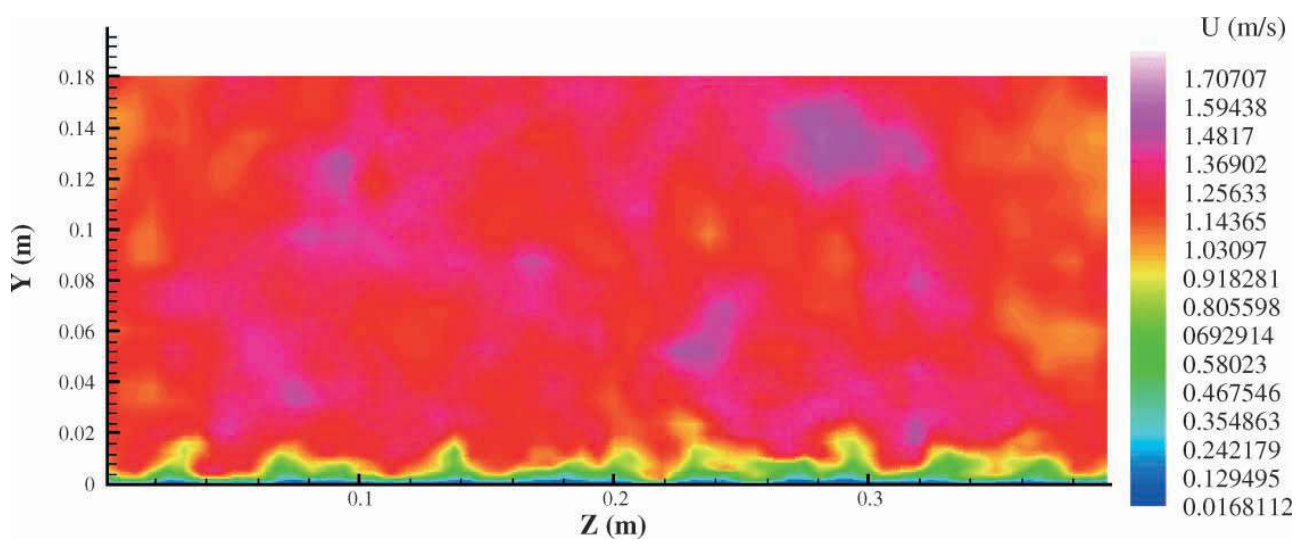

FIGURE 8 Instantaneous $z y$ plane $x$ velocity field at $R e_{x} \approx 40,000$; case E. (Colour version available to view online.) 


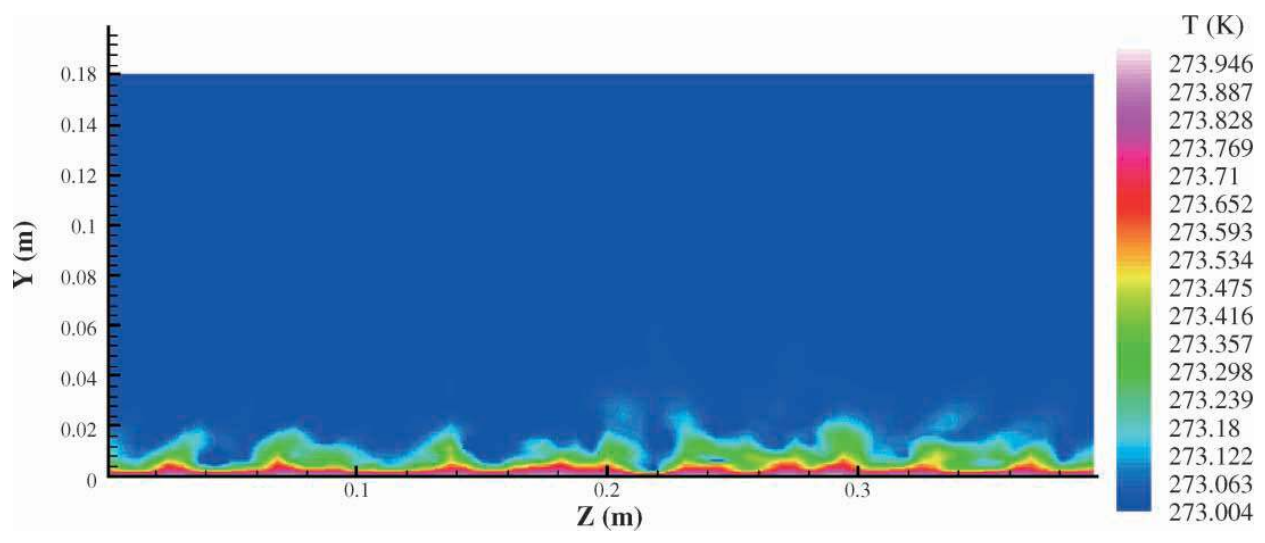

FIGURE 9 Instantaneous $z y$ plane temperature field at $R e_{x} \approx 40,000$; case E. (Colour version available to view online.)

(shown in Fig. 11), a progressive flattening of the velocity profile takes place inducing the formation of a wake. The wake formation was also observed experimentally by Dyban et al. (1977) and Dyban and Epick (1985) shown in Fig. 12.

Figure 13 shows a more pronounced flattening of the temperature profile compared to the velocity profile. This was reported in Péneau et al. (2000) and is confirmed here with the finer grid simulations presented for both lower turbulent levels and higher Reynolds numbers. At higher turbulence levels we can observe in Fig. 14 that for case E, the profile is closer to a turbulent profile even though no logarithmic region is yet apparent.

The spatial evolution of the boundary layer thicknesses is plotted in Figs. 15 and 16. The absence of discontinuities around $R e_{x} \approx 40,000$ proves, at least up to $R e_{x}=80,000$, that the consecutive simulations methodology used does not perturb the spatial evolution. It also shows that at a moderate turbulent level, there is no significant thickening of the boundary layer in contrast with higher turbulence levels. The thickening explains the flattening of the velocity profile and, consequently, the reduction of the displacement thickness and increase of momentum thickness. The corresponding phenomena for

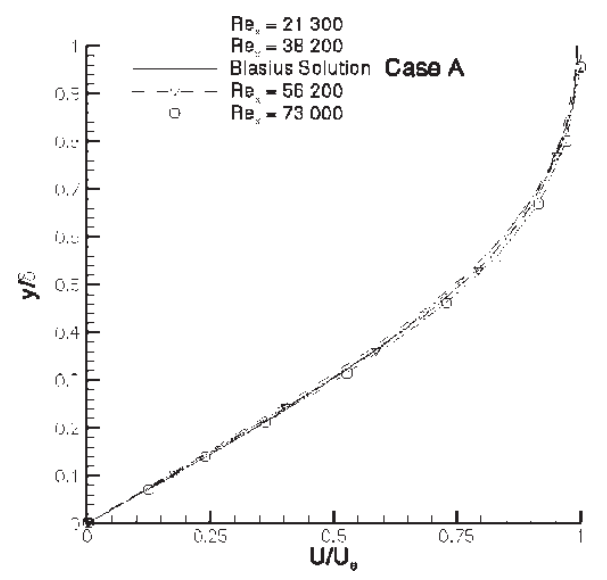

FIGURE 10 U velocity profile spatial evolution for case A. the thermal field are even more important, hence the higher flattening of the temperature profile (Fig. 17) when the boundary layer thickness is used for normalizing the data.

The higher thickening of the thermal boundary layer is explained by the value of the turbulent Prandtl number inside the boundary layer. As shown in Figs. 18 and 19, whereas $\operatorname{Pr}_{t}$ is close to 1 at low turbulence levels, $\operatorname{Pr}_{t}<1$ over most of the boundary layer at a higher turbulence level, such as in case E. This implies the thermal turbulent structures transfer more energy and hence generate higher fluctuations in their wake than the dynamic structures.

Although at low turbulence levels no thickening of the boundary layer and no flattening of the velocity profile is observed, there are nevertheless some important phenomena that occur inside the boundary layer. Figures 20-22 show that a rapid increase of the maximum turbulence level takes place inside the boundary layer, and values exceeding free-stream levels are attained. This points to a mechanism of turbulent energy production inside the boundary layer. These observations are consistent with the experimental measurements of Dyban et al. (1977) (see Fig. 23).

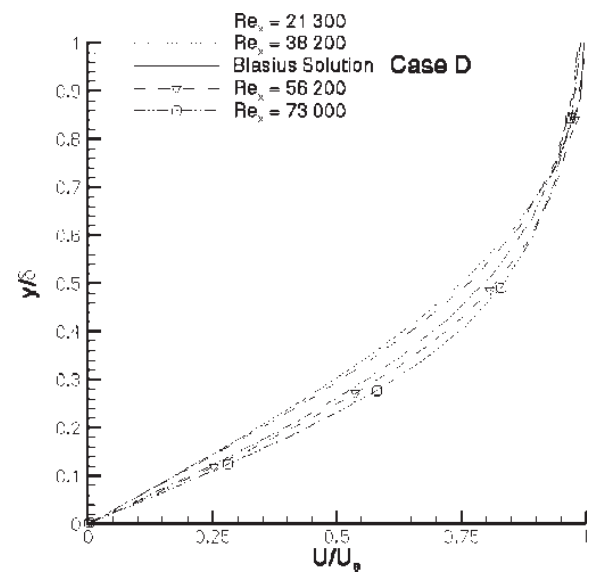

FIGURE 11 U velocity profile spatial evolution for case D. 


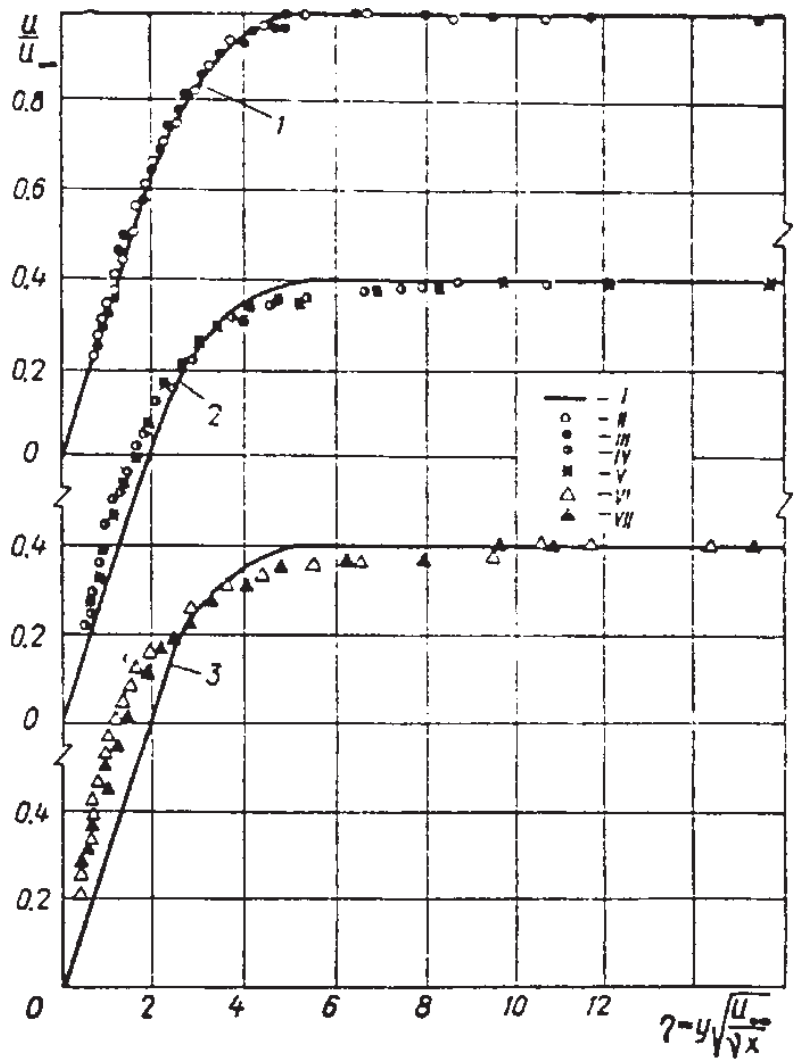

Fig. 1. Distribution of the velocities in the laminar boundary layer: I-Blasius profile; $\|-\mathrm{Re}_{\infty}=19,900, \sqrt{\left(\mathrm{U}_{\infty}^{\prime}\right)^{2}} / \mathrm{U}_{\infty}=0$ $0.3 \% ; I I I-R e_{\infty}=6,150, \sqrt{\overline{\left(u_{\infty}^{\prime}\right)^{2}}} / U_{\infty}=0.31 \% ; \mid V-R e_{\infty}=$ $19,950, \sqrt{\left(u_{\infty}^{\prime}\right)^{2}} / U_{\infty}=3.66 \% ; V-R e_{\infty}=6,160, \sqrt{\left(u_{\infty}^{\prime}\right)^{2}} / U_{\infty}=$ $4.41 \% ; V I-R e_{\infty}=19,900, \sqrt{\left(u_{\infty}^{\prime}\right)^{2}} / U_{\infty}=12.47 \% ; V I I-R e_{\infty}=$ $6,300, \sqrt{\left(u_{\infty}^{\prime}\right)^{2}} / U_{\infty}=9.69 \%$.

FIGURE 12 Extracted from Dyban et al. (1977) (legend from the article has been kept).

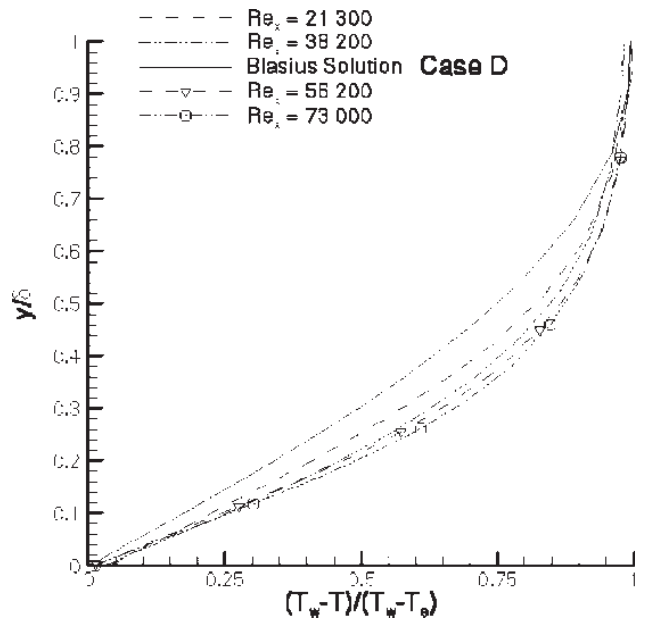

FIGURE 13 Temperature profile spatial evolution for case D.

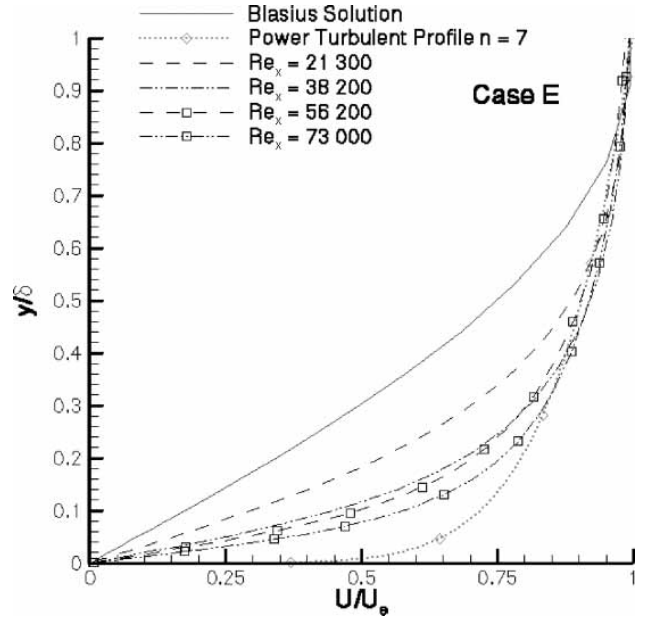

FIGURE 14 U velocity profile spatial evolution for case E. 


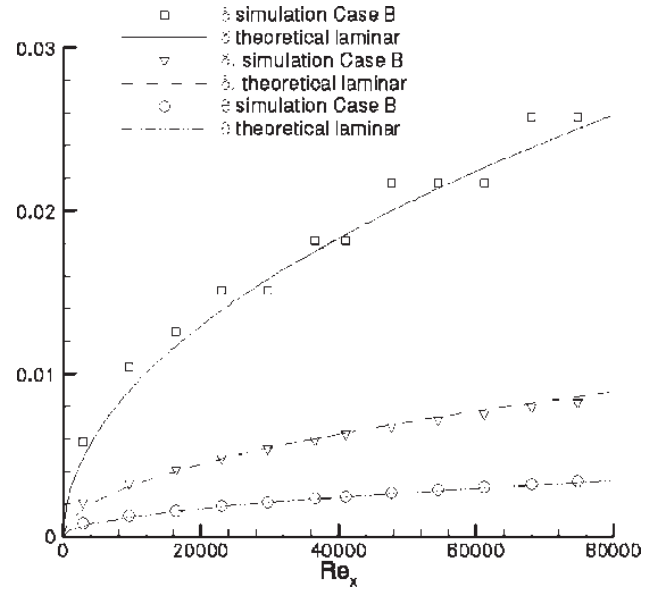

FIGURE 15 Spatial evolution of the boundary layer thicknesses (in m) for case B.

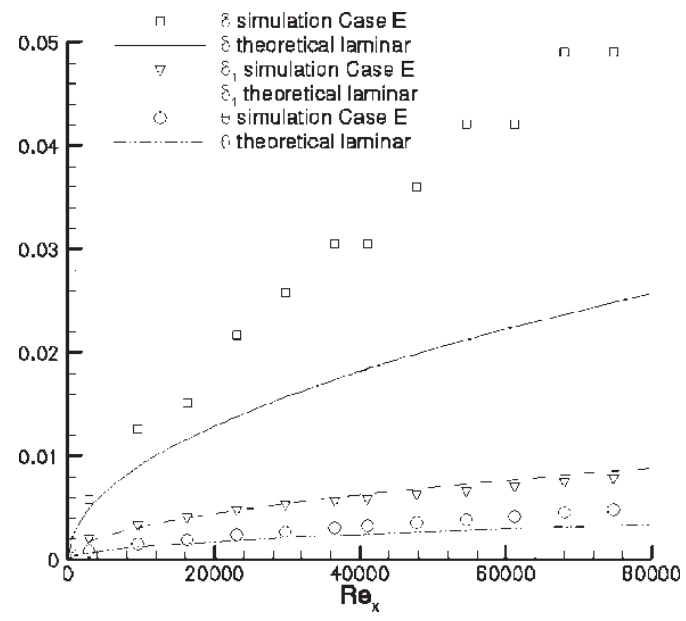

FIGURE 16 Spatial evolution of the boundary layer thicknesses (in m) for case $\mathrm{E}$.

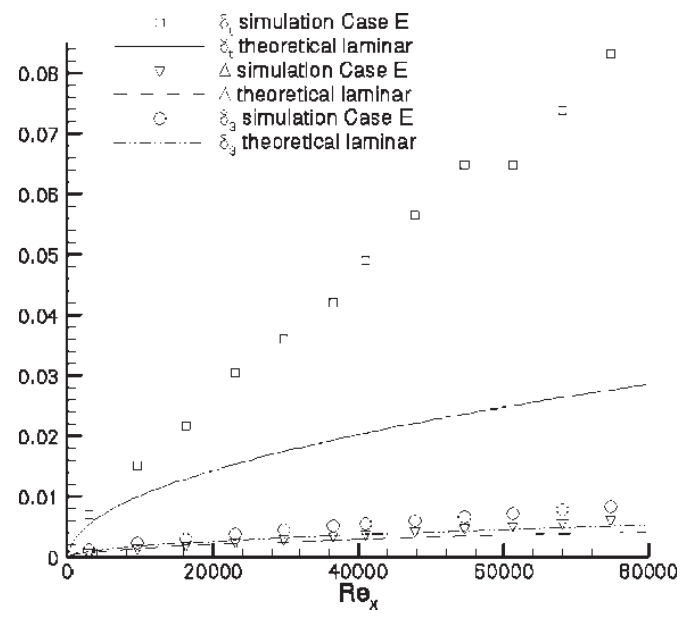

FIGURE 17 Spatial evolution of the thermal boundary layer thicknesses (in $\mathrm{m}$ ) for case $\mathrm{E}$.

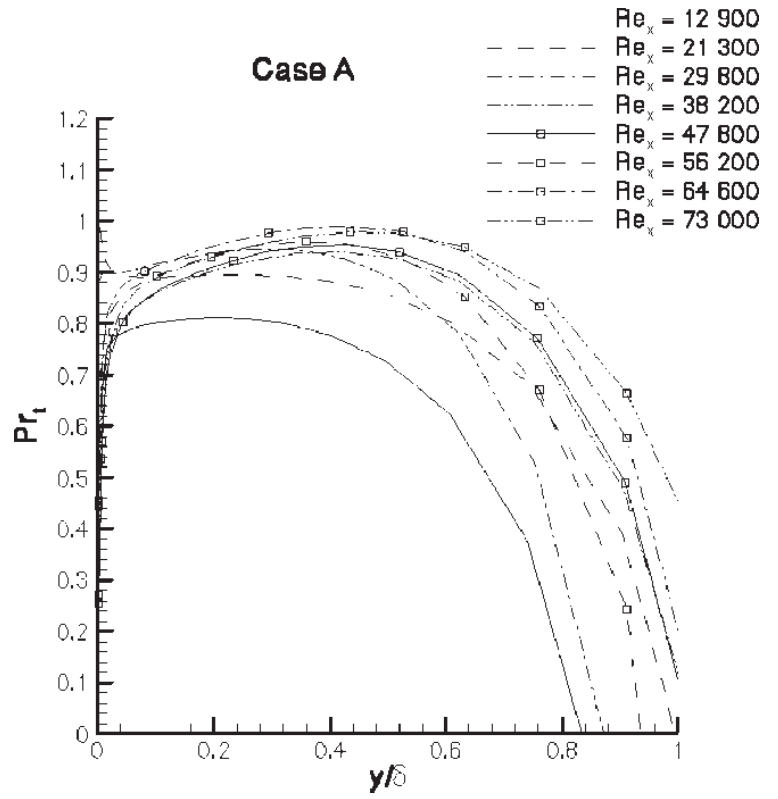

FIGURE 18 Spatial evolution of the turbulent Prandtl number for case A.

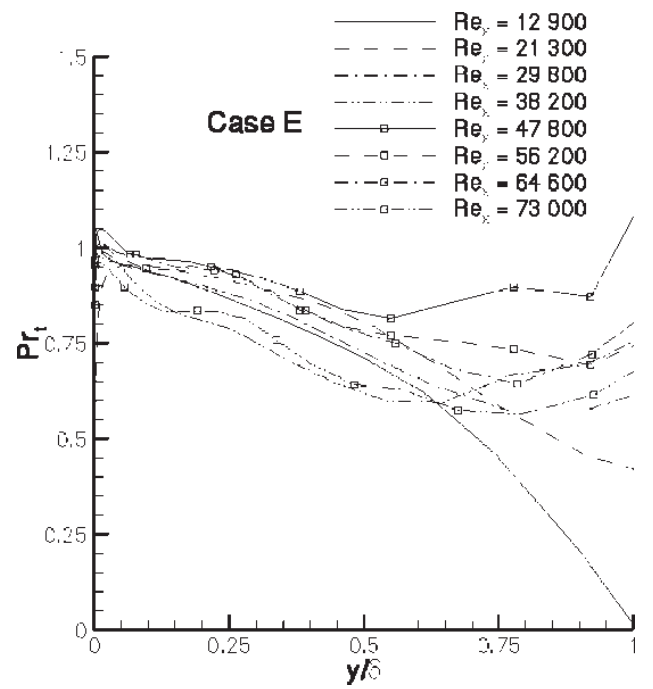

FIGURE 19 Spatial evolution of the turbulent Prandtl number for case E.

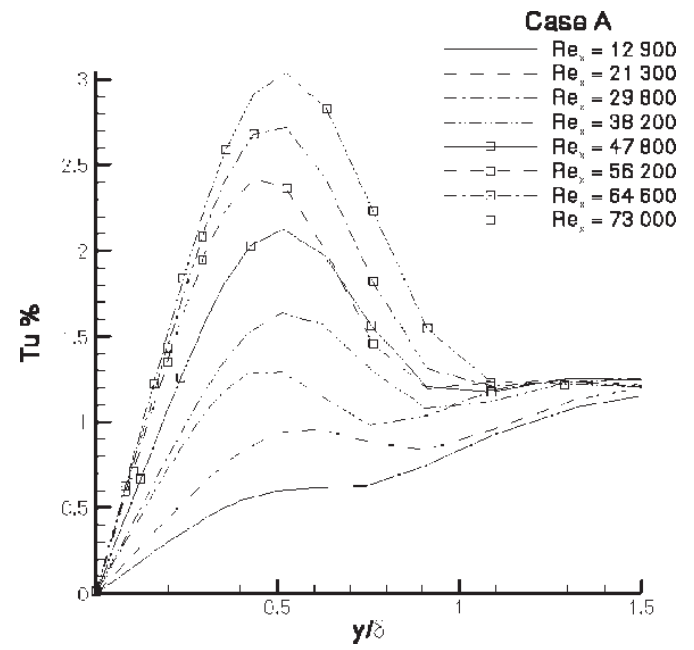

FIGURE 20 Spatial evolution of the turbulent level for case A. 


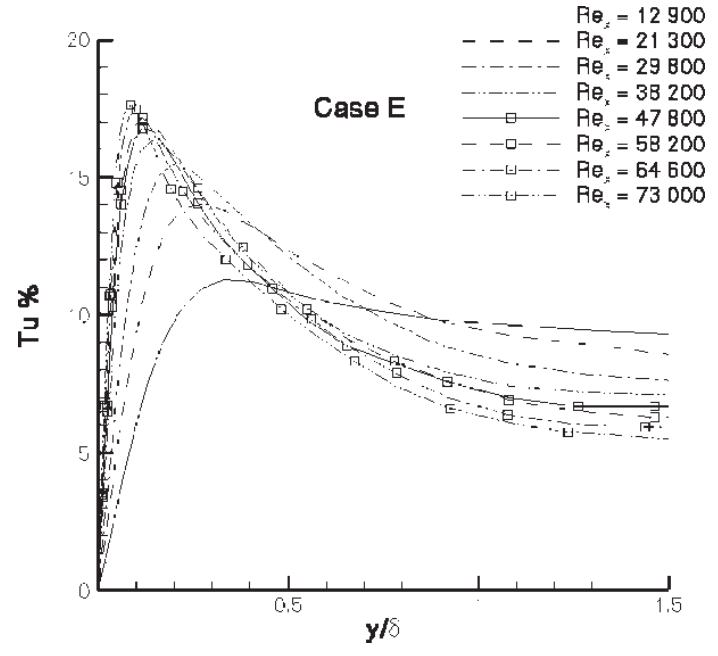

FIGURE 21 Spatial evolution of the turbulent level for case E.

The increase of $u_{\mathrm{rms}}$, and hence of $T u$, seems to come about partly from a transfer from $v_{\text {rms }}$ inside the boundary layer. A reorganization of the turbulent structures in this region must be the origin of this phenomenon.

Examination of the turbulence level profile shows that peak $T u$ levels inside the boundary layer are about three times the outside turbulence level for all cases presented at $R e_{x}=73,000$. Since initially the free-stream turbulent fields are substantially different, this is unlikely to be a coincidence.

The analysis of the turbulent energy production profiles reveals that $T u_{\max }$ correspond to the location of maximum

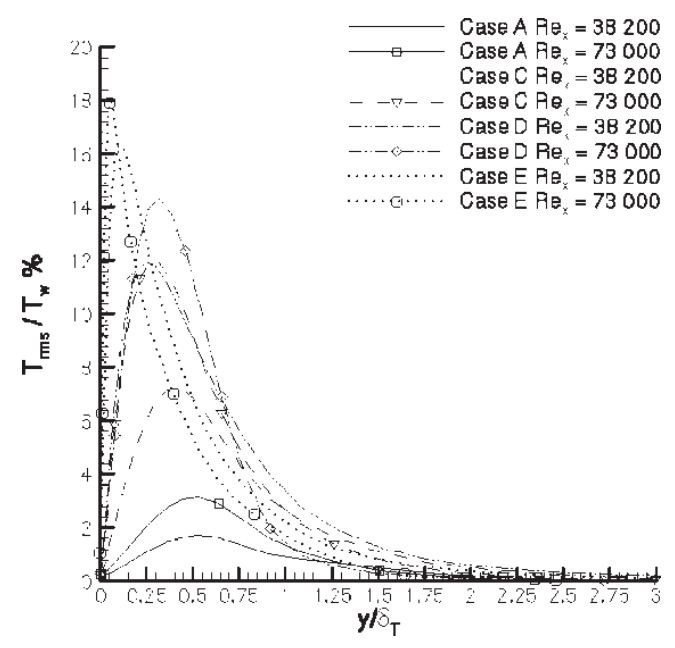

FIGURE 22 Thermal turbulent level for different cases.

turbulent energy production. Based on wall variables, this production is of the same order as the fully turbulent boundary layer. The preceding figures show how important the history of the development of the boundary layer under the free-stream turbulent field is in the analysis.

For the thermal boundary layer, we note in Fig. 22 that the thermal turbulent level is equal or slightly higher than $T u$ for the same case and Reynolds number. Outside the thermal boundary layer, temperature fluctuations are still present over a distance of at least $\delta_{\mathrm{T}}$ while the freestream thermal field is at constant temperature. This confirms the conclusion, drawn based on the turbulent

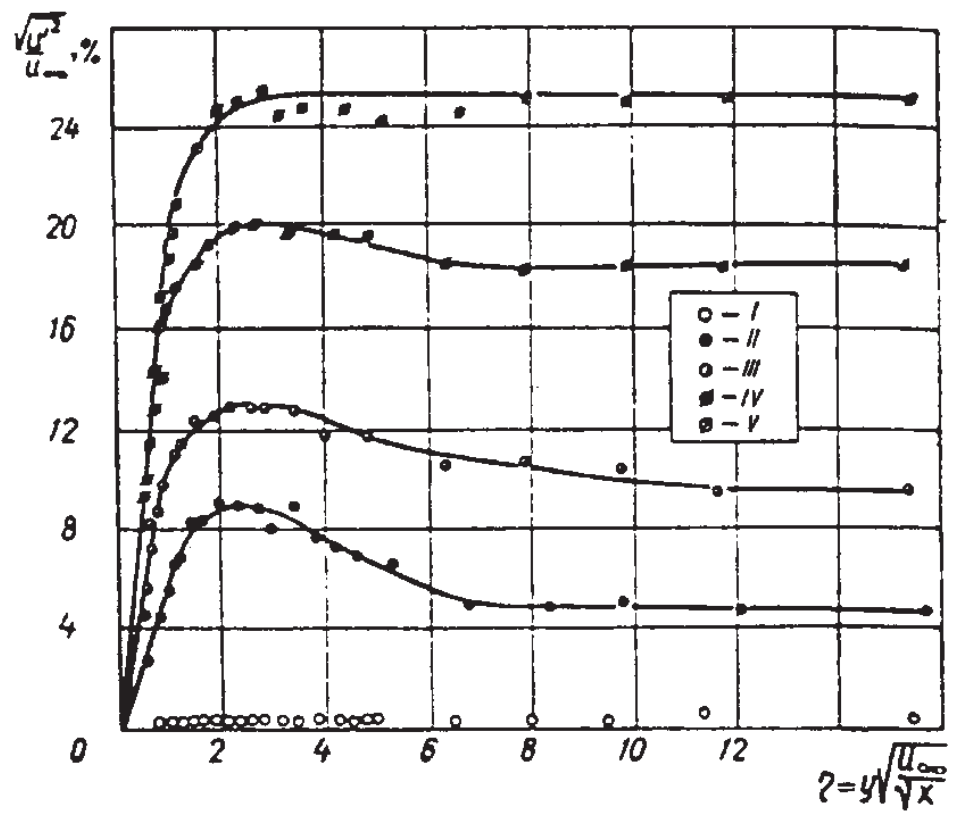

Fig. 3. Distribution of the pulsations in the laminar layer for $R e_{\infty} \cong 6.2 \cdot 10^{3}: 1-\sqrt{\left(u_{\infty}^{\prime}\right)^{2}} / U_{\infty}=0.31 \% ;\|-4.41 \% ;\| 11-$ 9.69\%: IV $-18.4 \%$; $V-25.2 \%$.

FIGURE 23 Extracted from Dyban et al. (1977) (legend from the article has been kept). 


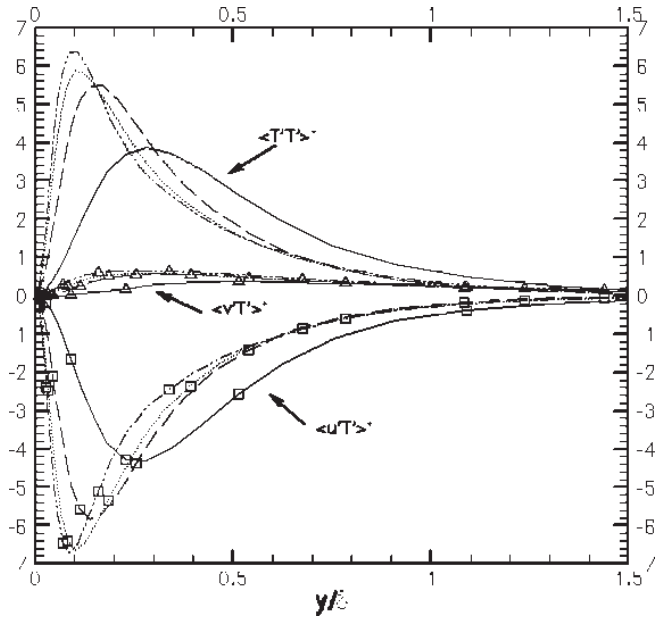

FIGURE 24 Spatial evolution of the velocity temperature correlation for case E. - $R e_{x}=16,800 ;----: R e_{x}=33,700 ; \cdots: R e_{x}=55,000$; --- $: \operatorname{Re}_{x}=71,900$.

Prandtl number, that the thermal boundary layer transfers more energy.

The analysis of the correlations $\left\langle T^{\prime} T^{\prime}\right\rangle,\left\langle u^{\prime} T^{\prime}\right\rangle$ and $\left\langle v^{\prime} T^{\prime}\right\rangle$ inside the boundary layer reveals that the temperature fluctuations are aligned with $v^{\prime}$. However, although up to the peak of $T u_{\max }$ the amplitude of $T_{\text {rms }}$ is directly correlated to $u_{\mathrm{rms}}$, after that point the correlation weakens until, in the wake of the boundary layer $\left\langle u^{\prime} T^{\prime}\right\rangle\left\langle\left\langle T^{\prime} T^{\prime}\right\rangle<\right.$ $\left\langle v^{\prime} T^{\prime}\right\rangle$ (see Figs. 24 and 25).

We deduce that the thermal fluctuations are convected by the $v$ velocity field and this explains why the temperature fluctuations do not vanish outside the boundary layer. From this analysis we can conclude that the $v$ velocity field feeds the thermal boundary layer in turbulent energy through the wake. $\left\langle w^{\prime} T^{\prime}\right\rangle$ is negligible throughout the computational domain.

Figures 26-29 show the impact of the above phenomena on wall shear stress and heat transfer

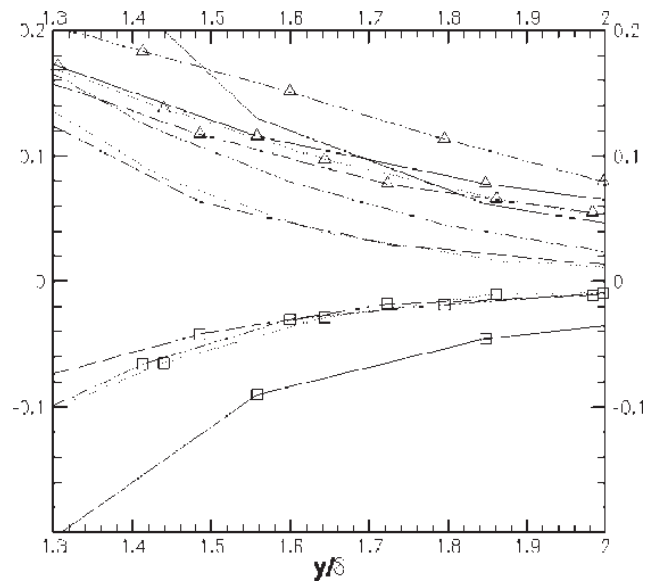

FIGURE 25 Spatial evolution of the velocity temperature correlation for case E. The same sign convention as in Fig. 24 is used -: $R e_{x}=16,800 ;---: R e_{x}=33,700 ; \cdots: R e_{x}=55,000 ;---$ : $\operatorname{Re}_{x}=71,900$.

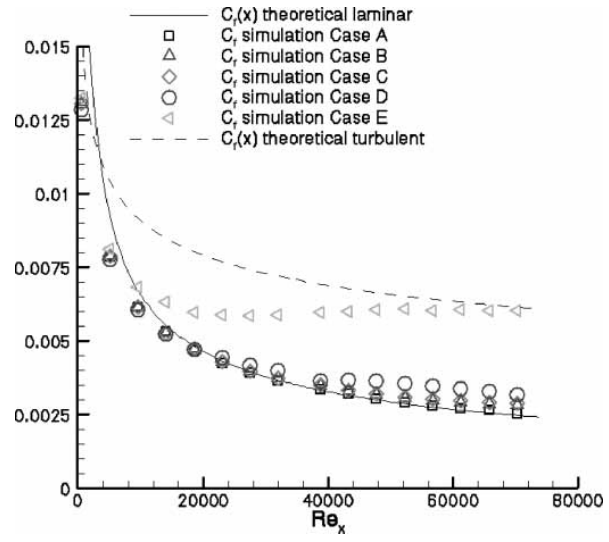

FIGURE 26 Influence of the free-stream turbulence on the friction coefficient.

coefficients, both of which are above the laminar values for $R e_{x}>20,000$. This increase is linked to the amplitude of the free-stream turbulence level. For the case E, $C_{f}$ and $S t$ reach the turbulent value at $R e_{x} \approx 70,000$ or $R e_{\theta} \approx 200$. For this case we note that wall coefficients do not change much for $R e_{x}>$ 20,000 , and as a first step to correlate wall transfer and free-stream turbulence a fit of the form $\sqrt{R e_{x}}$ is proposed for $C_{f} / C_{f 1 \mathrm{am}}$ and $\mathrm{St} / \mathrm{St}_{\mathrm{lam}}$ in Figs. 30 and 31.

Cases B and C in these figures exhibit the same increase of wall transfer and with no influence of the dissipative length scale. Furthermore, the temperature field is no more sensitive to free-stream turbulence than the velocity field since the same expressions fit the data. This appears to be in contradiction with the numerical and experimental observations. The answer to this contradiction lies in the rapid thickening of the boundary layers observed previously. Indeed, if instead of expressing the laminar value of $C_{f}$ and $\mathrm{St}$ in terms of $R e_{x}$, we express them in

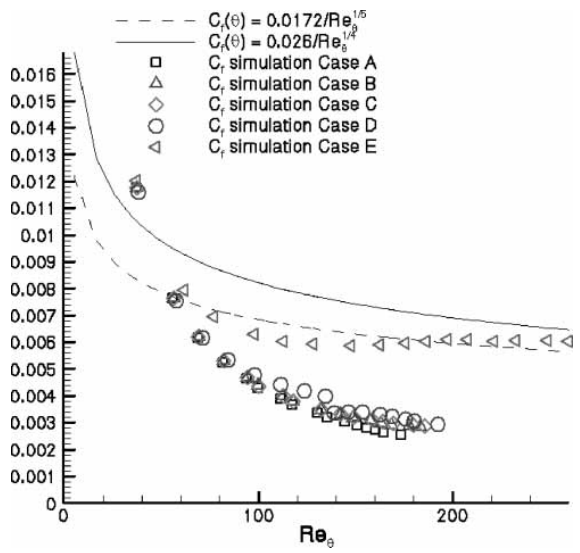

FIGURE 27 Influence of the free-stream turbulence on the friction coefficient based on the momentum thickness. 


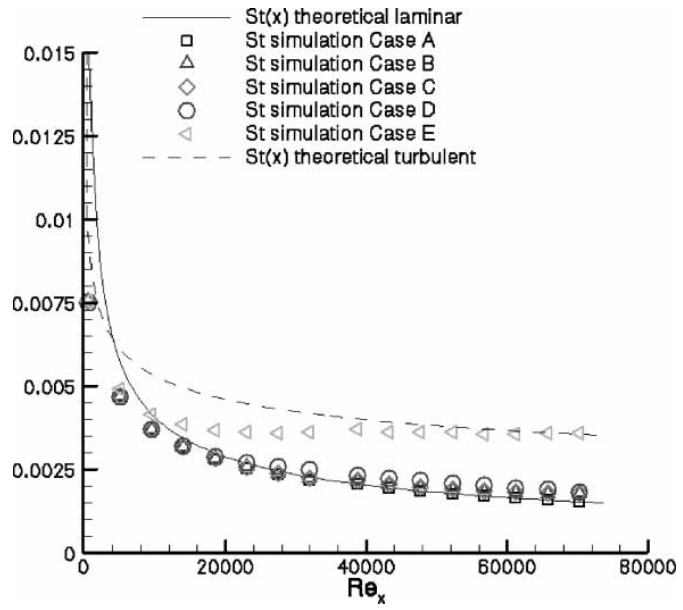

FIGURE 28 Influence of the free-stream turbulence on the Stanton number.

terms of $\delta(x)$, namely $C_{f}(x)=(3.32 \nu) /\left(U_{e} \delta(x)\right)$ and $\mathrm{St}(x)=(1.66 D) /\left(U_{e} \delta_{T}(x)\right)$, we then obtain a completely different picture as shown in Figs. 32-35, and comparison between Figs. 33 and 35 does indeed reveal the higher sensitivity of the thermal field to free-stream turbulence.

The evolution of $C_{f} / C_{f 1 \mathrm{am}}$ and $\mathrm{St} / \mathrm{St}_{\mathrm{lam}}$ is also quite different as a linear variation is a good fit for the thermal field but a poor one for the dynamic field. The $500 \%$ increase for the Stanton number in Fig. 35 at $R e_{x}=$ 60,000 does not represent the actual enhancement since the comparison is between two different boundary layers of the same thickness with and without free-stream turbulence. Locally, the heat transfer increase is of the order of $200 \%$ as shown in Fig. 31. This illustrates nonetheless the fastest spatial development of the thermal boundary layer. It is reasonable to expect that transition to turbulence for the thermal boundary layer might occur

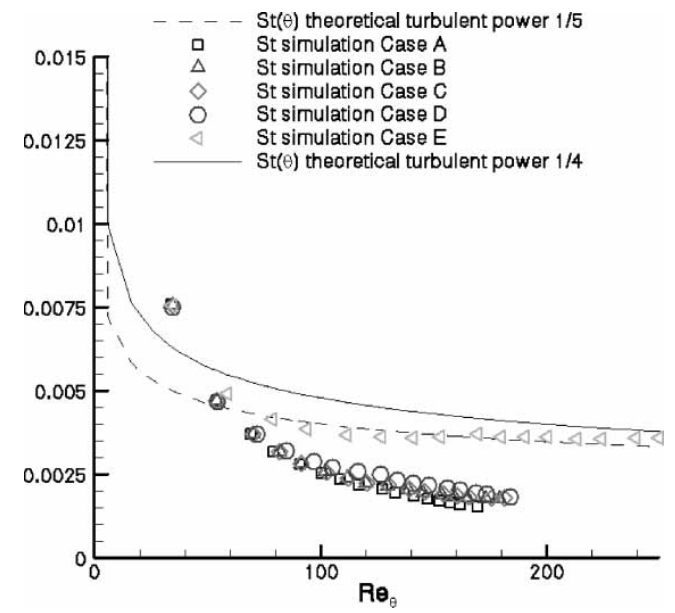

FIGURE 29 Influence of the free-stream turbulence on the Stanton number based on the momentum thickness.

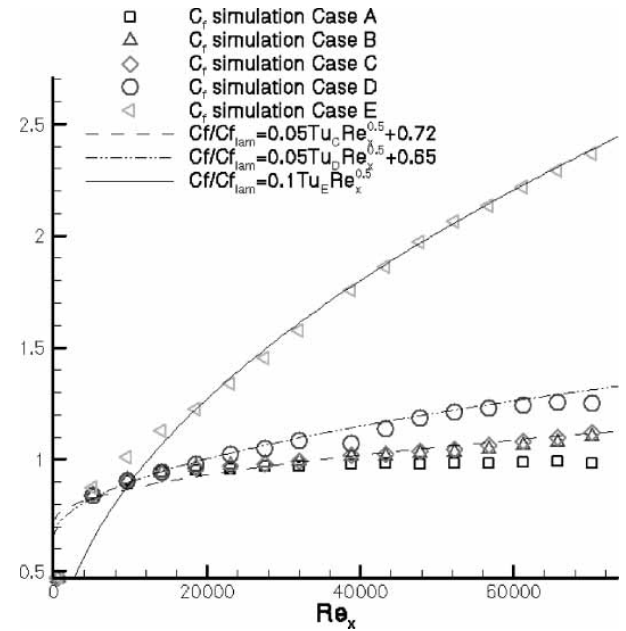

FIGURE 30 Friction coefficient ratio.

earlier, spatially speaking, since the thicker a boundary layer, the more unstable it is.

\section{CONCLUSIONS}

The influence of free-stream turbulence on the development of a boundary layer was investigated using LES. The experimental observations of Dyban et al. (1977), Dyban and Epick (1985) and Bradshaw et al. and others are well reproduced by the simulations, and detailed analysis of the LES data provides an explanation for many of these observations. The simulations also underscore the higher sensitivity of the thermal field to free-stream turbulence.

For all five cases presented here, bypass transition is found to occur in the early stage of the boundary layer development. Even if all the characteristics of a fully

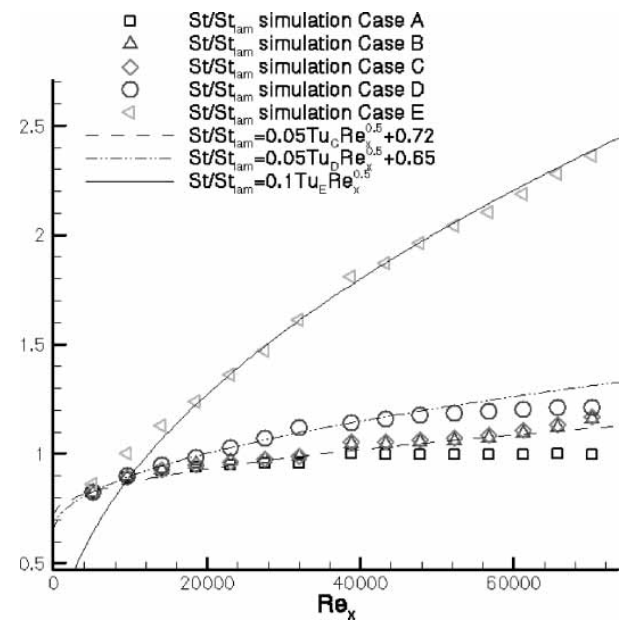

FIGURE 31 Stanton number ratio. 


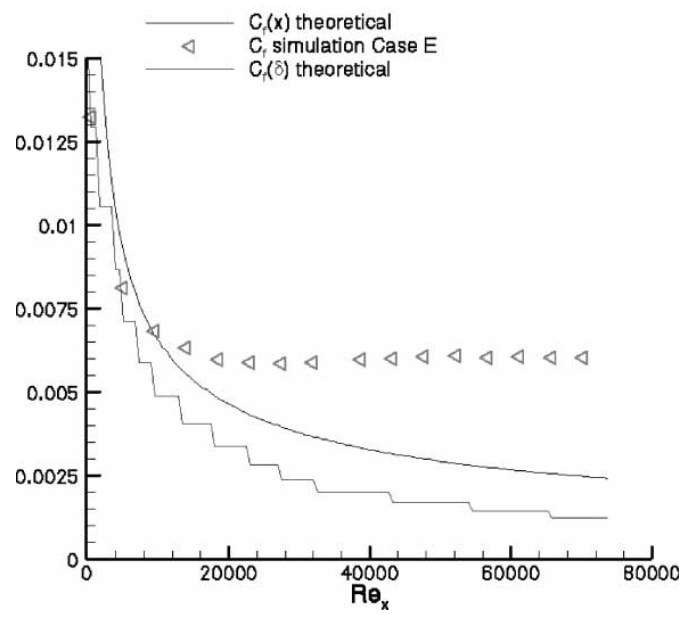

FIGURE 32 Influence of the free-stream turbulence on the friction coefficient based on the boundary layer thickness.

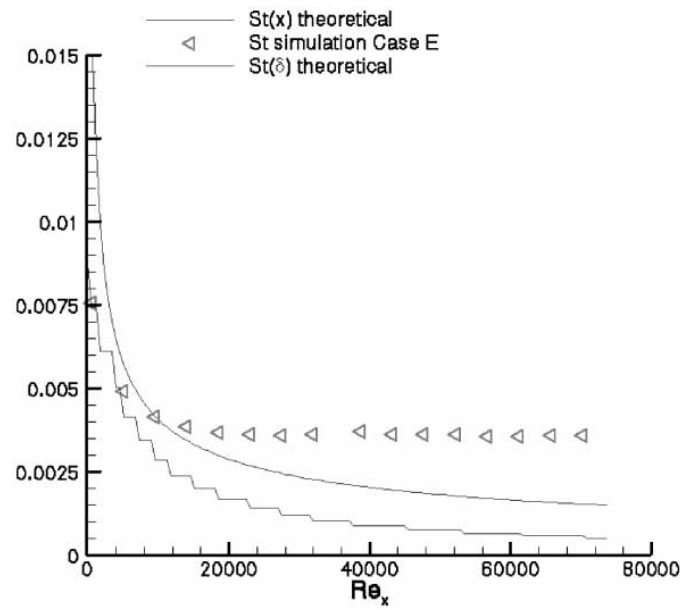

FIGURE 33 Influence of the free-stream turbulence on the Stanton number based on the thermal boundary layer thickness.

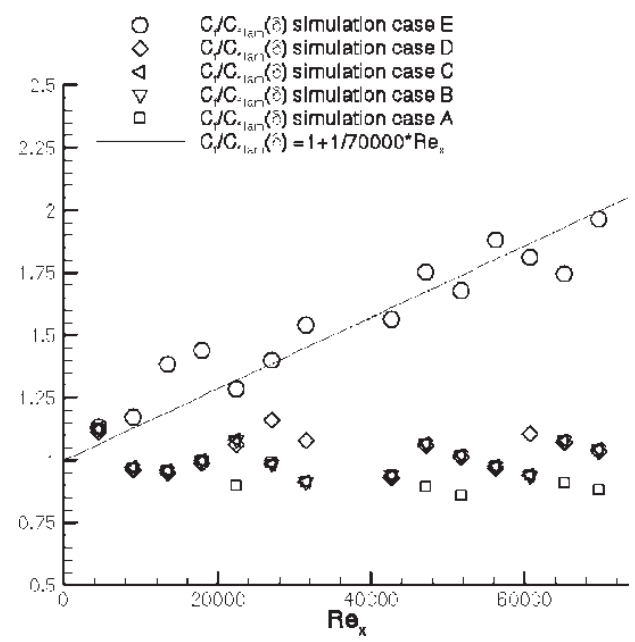

FIGURE 34 Friction coefficient ratio based on the boundary layer thickness.

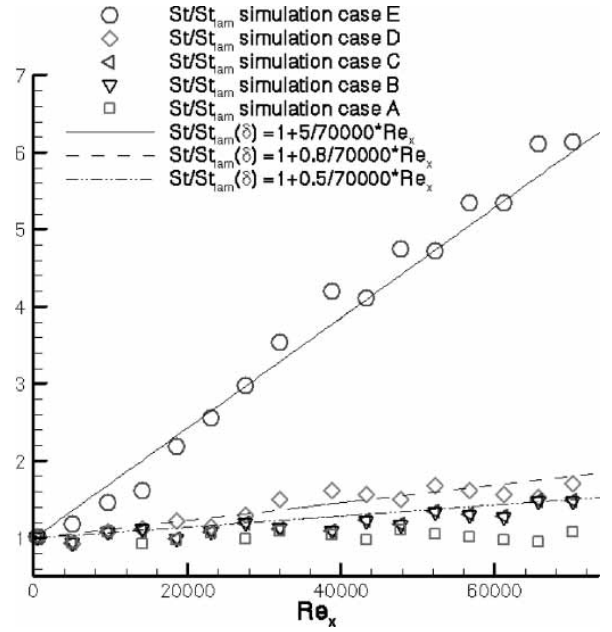

FIGURE 35 Stanton number ratio based on the thermal boundary layer thickness.

turbulent boundary layer are not yet observable, the high level of turbulent intensity as well as the important flattening of the mean velocity and temperature profile suggest that, at least for case $\mathrm{E}(T u \approx 10 \%)$, the transition to turbulence takes place at a relatively low Reynolds number. Simulations in progress appear to confirm this point.

The next phase of this work is to simulate the interaction of the free-stream turbulence with the boundary layer region up to a Reynolds number where fully turbulent flow occurs to allow comparison with data from ongoing parallel investigation at INRA by Kondjoyan.

\section{References}

Baskaran, V., Abdellatif, O.E. and Bradshaw, P. (1989) "Effects of freestream turbulence on turbulent boundary layers with convective heat transfer", In: University, S., ed, Seventh Symposium on Turbulent Shear Flows.

Blair, M.F. (1983a) "Influence of free-stream turbulence on turbulent boundary layer heat transfer and mean profile development. Part IExperimental Data", Journal of Heat Transfer 105, 33-40.

Blair, M.F. (1983b) "Influence of free-stream turbulence on turbulent boundary layer heat transfer and mean profile development. Part IIanalysis of results", Journal of Heat Transfer 105, 41-47.

Bradshaw, P. (1974). Effect of free-stream turbulence on turbulent shear layers, I.C., Aero Report 74-10, Imperial College of Science and Technology, Department Aeronautics, Prince Consort Road, London SW7 2BY.

Calmet, I. and Magnaudet, J. (1996) "Large eddy simulation of high Schmidt number mass transfer in a turbulent channel flow", Phys. Fluids 9(2), 438-455.

Charnay, G., Comte-Bellot, S. and Mathieu, J. (1971) "Development of a turbulent boundary layer on a flat plate in an external turbulent flow", ACARD Conf. Proc., 93.

Charnay, G., Comte-Bellot, S. and Mathieu, J. (1972) "Etat des Contraintes et des Fluctuations de Vitesse dans une Couche Limite Perturbée", C.R. Acad. Sci. A 274, 1643.

Charnay, G., Comte-Bellot, S. and Mathieu, J. (1976) "Response of turbulent boundary layer to random fluctuations in the external stream", Phys. Fluids 19(9), 1261-1271. 
Dyban, E.P. and Epick, E.Y (1985). Transferts de Chaleur et Hydrodynamique dans les Ecoulements Rendus Turbulents. Monograph translated from Russian at I.N.R.A., available from A. Kondjoyan.

Dyban, E.P., Epick, E.Y. and Surpun, T.T. (1977) "Characteristics of the laminar layer with increased turbulence of the outer stream", Int. Chem. Eng. 17(3), 501-504.

Fage, A. and Falkner, V.M. (1931) "On the relationship between heat transfer and surface friction for laminar flow", Br. Aero. Res. Council $R$ and $M, 1408$.

Hancock, P.E. and Bradshaw, P. (1983) "The effect of freestream turbulence on turbulent boundary layers", J. Fluids. Eng. 105, 284-289.

Hancock, P.E. and Bradshaw, P. (1989) "Turbulence structure of a boundary layer beneath a turbulent free-stream”, J. Fluid. Mech. 205, $45-76$.

Kondjoyan, A., Péneau, F. and Boisson, H.C. (2002) "Effect of high free-stream turbulence on heat transfer between plates and air flows: a review of existing experimental results", Int. J. Therm. Sci. 41, 1-16.

Maciejewski, P.K. and Moffat, R.J. (1992) "Heat transfer with very high free-stream turbulence: part II analysis of the results", ASME J. Heat Transfer 114, 834-839.
Meier, H.U. and Kreplin, H.P. (1980) "Influence of free-stream turbulence on boundary-layer development", AIAA 18(1), 11-15.

Pédisius, A.A., Kazimekas, P.V. and Slanciauskas, A.A. (1979) "Heat transfer from a plate to a high-turbulence airflow", Heat Transfer Soviet Res. 11(5), 125-134.

Péneau, F., Legendre, D., Magnaudet, J. and Boisson, H.C. (1999) "Large eddy simulation of a spatially growing boundary layer using a dynamic mixed subgrid-scale model", Symposium ERCOFTAC on Direct and Large Eddy Simulation, (Cambridge).

Péneau, F., Boisson, H.C. and Djilali, N. (2000) "Large eddy simulation of the influence of high free-stream turbulence on a spatially evolving boundary layer", Int. J. Heat and Fluid Flow 21, 640-647.

Simonich, J.C. and Bradshaw, P. (1978) "Effect of free-stream turbulence on heat transfer through a turbulent boundary layer", Trans. ASME J. of Heat Transfer 100, 671-677.

Smagorinsky, J. (1963) "General circulation experiments with the primitive equations", Mon. Weather Rev. 93, 99.

Young, C.D., Han, Y., Huang, Y. and Rivir, R.B. (1992) "Influence of jet grid turbulence on flat plate turbulent boundary layer and heat transfer", J. Heat Transfer 114, 64-72.

Zang, Y., Street, R.L. and Koseff, J.R. (1993) "A dynamic mixed subgridscale model and its application to turbulent recirculating flows", Phys. Fluids A5(12), 3186-3196. 